\title{
Women Living With Breast and Cervical Cancer in the Community: The Face of Surabaya Nowadays
}

\author{
Ni Putu Wulan Purnama Sari
}

Department of Palliative Nursing, Faculty of Nursing, Widya Mandala Catholic University Surabaya, Indonesia

\section{ARTICLE INFO}

Article history:

Received : 30 November 2018

Reviewed: 30 December 2018

Accepted : 22 January 2019

\section{Keywords:}

breast cancer, cancer diagnosis, cancer situation, cancer stage, cancer therapy, cervical cancer.
*Corresponding author:

Ni Putu Wulan Purnama Sari

Department of Palliative Nursing,

Faculty of Nursing, Widya Mandala

Catholic University Surabaya,

Indonesia.

Jl. Raya Kalisari Selatan 1, Pakuwon

City, Surabaya, Indonesia

Email:

wulanpurnama@ukwms.ac.id

\begin{abstract}
A B S TRACT
Background: Cervical cancer and breast cancer are the two top leading cases of female cancer in Indonesia. Being the 2nd largest city in Indonesia, Surabaya is being populated by more than 1.5 million females in 2017. This study aimed to describe the demographic characteristic of women living with cervical and breast cancer in order to show the current picture of female cancer situation in Surabayan communities nowadays. Substantial to it, the correlation between time of first diagnosis and type of therapy with current stage of cancer were analyzed to evaluate the cancer management effectiveness in community context.
\end{abstract}

Methods: This cross-sectional study involved six (9.68\%) Public Health Centers (PHCs) among 62 PHCs in Surabaya, Indonesia, which were selected by one stage cluster random sampling. There were 140 and 139 women living with cervical and breast cancer participated in this study respectively $(n=279)$. Self-developed demographic questionnaire was used to collect the data. Descriptive statistic, Spearman Rank correlation test, and Mann-Whitney $\mathrm{U}$ test were used in data analysis $(\alpha<.05)$.

Results: Overall, most respondents were married $(77.06 \%)$ and were housewives (59.14\%). They were high school graduated at majority (44.44\%). Family support came from spouse and children (70.25\%). Those with breast cancer mostly aged middle-up adulthood (56.12\%), while older aged were found in respondents with cervical cancer (72.86\%). The majority had been diagnosed with cancer for less than five years (81.36\%), but there was a tendency that the longer life expectancy was found in those with cervical cancer. More cervical cancer respondents with advanced stage were found to be long-term survivors (25\%). The first time of diagnosis and the type of therapy were significantly different between cases $(p=.039$ and $p=.000$ respectively), but the current stage of cancer was not significantly different $(p=.239)$. There was a quite strong correlation between time of first diagnosis and current stage of cancer ( $\rho=$ -.409; $p=.000$ ), but there was no significant correlation between type of therapy and current stage of cancer $(p=.147)$.

Conclusions: The demographic characteristic of women living with cervical and breast cancer has been slowly shifting from elderly or late adulthood, to middle and early adulthood. The first time of diagnosis and the type of therapy were significantly different between cases, but the current stage of cancer was not significantly different. There was a strong significant correlation between time of first diagnosis and current stage of cancer in cervical and breast cancer.

\section{INTRODUCTION}

Cancer is defined as a disease in which certain genes that control the process of cell regeneration in the human body become damaged and grow abnormally (1). Breast and cervical cancers have emerged as major global health challenges and disproportionately lead to excess morbidity and mortality in low- and middle-income countries when compared to high-income countries (2). Breast and cervical cancers are the commonest cancers diagnosed in women living in low-income and middle-income countries, where opportunities for prevention, early detection, or both, are few (3). 
Every year, more than two million women worldwide are diagnosed with breast or cervical cancer, yet where a woman lives, her socioeconomic status, and agency largely determines whether she will develop one of these cancers and will ultimately survive (4). Generally, the stage of survivorship in cancer categorizes into three, namely: acute ( $<1$ year), short term (1-5 years), and long term survivorship ( $>5$ years) (5). Nowadays, we could see many cervical and breast cancer survivors (CCSs and BCSs) in our surroundings due to the advances in cancer diagnosis and therapy, and the integrated system of care implemented in clinical and community setting.

It can be estimated that the incidence of cancer in Indonesia is $0.1 \%$ of the population, and more than $50 \%$ of cancer patients firstly come to seek for medication in an advanced stage (6). Based on national cancer situation in 2013, almost all age groups have a high prevalence of cancer (various cases). The highest cancer prevalence was in the elderly age group of 75 years old and above, which was equal to $5 \%$; and the lowest prevalence was in the children age groups of 1-4 years old and 5-14 years old, which was equal to $0.1 \%$; but there was a high increase in the age group of 25-34, 3544 , and $45-54$ years old requiring special attention (7).

Cervical cancer usually takes about 10 to 20 years to develop and is frequently induced by human papilloma virus (HPV) infection due to unsafe sex and frequent sex partner changes (8); while breast cancer occur in younger or reproductive age because at those age most women produce breast milk due to pregnancy (9). About 8 in 10 women with invasive breast cancer have infiltrating ductal carcinoma (the most common type) which starts and spreads from the milk duct, while about 1 in 10 women with invasive breast cancer have infiltrating lobular carcinoma which starts and spreads from the milk-producing lobule (9).

In 2013, the prevalence of cancer in Indonesia was $1.4 \%$; prevalence of breast and cervical cancer was $0.8 \%$ and $0.5 \%$ respectively; states of Riau Islands, North Maluku, and Yogyakarta had the highest prevalence of cervical cancer which was equal to $1.5 \%$, while the highest prevalence of breast cancer was in the state of Yogyakarta which was equal to $2.4 \%$; based on the estimation of the number of women with cervical cancer and breast cancer mostly were found in East Java and Central Java (7). In 2017, breast cancer reached the 1 st position as the highest new cases and deaths in Indonesian cancer statistics, followed by cervical cancer in 2nd position (2) (detail explanation about Indonesia's cancer profiling in 2017 was not available online yet). In the period of four years we could see that it was pretty difficult for the national government to deal with cervical and breast cancer, and to make significant improvement in national cancer situation, but continuous efforts have been made to reach the goals.
In the management of female cancer in community setting in Surabaya, Public Health Centre (PHC) plays a key role in delivering primary care services towards CCSs and BCSs. In the era of national health coverage, Indonesia focuses national health intervention into strategic health promotion and prevention efforts to decrease the national loss due to curative and rehabilitative efforts related to chronic illness management, especially cancer in this context. Aggressive cancer promotion and prevention strategy in primary care setting should be immediately implemented into public to slowly reduce the country's loss. Therefore, for authority of Surabaya in this context, the current picture of demographic characteristic of women living with breast and cervical cancer is being important to be identified, so that the target population of those promotion and prevention program could be pointed accurately. This study aimed to describe the demographic characteristic of women living with cervical and breast cancer in Surabaya in order to show the current picture of female cancer situation in communities around Surabaya nowadays. Data on demography would allow identification of appropriate and timely screening procedures, determination of best course of action for prevention and treatment, and improvement of the quality of life.

Substantially, the correlation between time of first diagnosis and type of therapy with current stage of cancer were analyzed to evaluate the cancer management effectiveness related to the disease progressivity and clinical manifestation. This is important for predicting the individual symptom burden, health-related quality of life, caregiver burden, and general evaluation of cancer management effectiveness contributing to national health expenditure. Results of this study may potentially affect the strategic health promotion and prevention program from various PHCs acting as the first responder towards emerging public health problems, especially women's reproductive health in this context. Finally, this paper was made to understand better the current situation and public health response to cervical and breast cancer in the community of Surabaya.

\section{METHODS}

There are 62 Public Health Centers (PHC) spread all over Surabaya today, making it possible to get the big picture of demographic characteristic of women living with breast and cervical cancer in the community nowadays. This cross-sectional study involved six PHCs (9.68\%) in Surabaya, Indonesia, selected by one stage cluster random sampling; namely PHC of Rangkah, Gading, Pacar Keling, Pucang Sewu, Kedungdoro, and Mulyorejo. There were 140 and 139 women living with cervical and breast cancer participated in this study 
respectively $(\mathrm{n}=279)$. Inclusion criteria was adult ( $>18$

$\mathrm{PHC}$, and regularly home-visited by a palliative volunteer under the supervision of respectable PHC. Exclusion criteria were rejection on filling out the consent form. Data were collected since February until March 2018. Self-developed demographic questionnaire was used to collect the data. Descriptive statistic, Spearman Rank correlation test, and Mann-Whitney $U$ test were used in data analysis $(\alpha<.05)$. Ethical clearance was issued by Faculty of Nursing, Universitas Airlangga, Surabaya, Indonesia, with number of 681-KEPK.

\section{RESULTS}

Overall, most respondents were married (77.06\%) and were housewives (59.14\%). They were high school years old), cancer diagnosis has been confirmed by the graduated at majority (44.44\%). Family support mostly came from spouse and children (70.25\%). Those with breast cancer mostly aged middle-up adulthood (56.12\%), while older aged were found in respondents with cervical cancer (72.86\%). Mean of age was 53.36 and 49.01 years old for cervical and breast cancer respectively; breast cancer seemed to occur at earlier age than cervical cancer. The demographic characteristic of women living with cervical and breast cancer has been slowly shifting from elderly or late adulthood to middle and early adulthood compared to the national cancer situation in 2013. Table 1 below shows the demography characteristic of study respondents in details.

Table 1. Patient's characteristics

\begin{tabular}{|c|c|c|c|c|}
\hline \multirow{2}{*}{ Characteristics } & \multicolumn{2}{|c|}{ Cervical cancer $(n=140)$} & \multicolumn{2}{|c|}{ Breast cancer ( $n=139)$} \\
\hline & Frequency & $\%$ & Frequency & $\%$ \\
\hline \multicolumn{5}{|l|}{ Age (years old) } \\
\hline 17-25 (late adolescent) & 1 & 0.71 & 6 & 4.32 \\
\hline 26-35 (early adulthood) & 2 & 1.43 & 11 & 7.91 \\
\hline 36-45 (middle adulthood) & 22 & 15.71 & 37 & 26.62 \\
\hline 46-55 (late adulthood) & 56 & 40.00 & 41 & 29.50 \\
\hline 56-59 (pre-elderly) & 13 & 9.29 & 13 & 9.35 \\
\hline 60-74 (elderly) & 46 & 32.86 & 27 & 19.42 \\
\hline $75-90$ (old) & 0 & 0.00 & 4 & 2.88 \\
\hline \multicolumn{5}{|l|}{ Educational background } \\
\hline Primary school & 36 & 25.71 & 24 & 17.27 \\
\hline Secondary school & 34 & 24.29 & 16 & 11.51 \\
\hline High school & 49 & 35.00 & 75 & 53.96 \\
\hline Diploma / Bachelor degree & 15 & 10.71 & 22 & 15.83 \\
\hline Uneducated & 6 & 4.29 & 2 & 1.44 \\
\hline \multicolumn{5}{|l|}{ Marital status } \\
\hline Single & 5 & 3.57 & 18 & 12.95 \\
\hline Married & 124 & 88.57 & 91 & 65.47 \\
\hline Widow & 10 & 7.14 & 30 & 21.58 \\
\hline Divorce & 1 & 0.71 & 0 & 0.00 \\
\hline \multicolumn{5}{|l|}{ Living at home with } \\
\hline Spouse & 54 & 38.57 & 28 & 20.14 \\
\hline Children & 12 & 8.57 & 28 & 20.14 \\
\hline Spouse + children & 29 & 20.71 & 45 & 32.37 \\
\hline Parents & 1 & 0.71 & 28 & 20.14 \\
\hline Sibling & 0 & 0.00 & 4 & 2.88 \\
\hline Alone & 8 & 5.71 & 3 & 2.16 \\
\hline Extended family & 36 & 25.71 & 3 & 2.16 \\
\hline \multicolumn{5}{|l|}{ Occupation } \\
\hline Civil servant & 10 & 7.14 & 2 & 2.16 \\
\hline Entrepreneur & 10 & 7.14 & 6 & 4.32 \\
\hline Private employee & 7 & 5.00 & 29 & 20.86 \\
\hline Housewife & 81 & 57.56 & 84 & 60.43 \\
\hline Farmer & 1 & 0.71 & 1 & 0.72 \\
\hline Tailor & 0 & 0.00 & 3 & 2.16 \\
\hline Unemployed/retired & 31 & 22.14 & 14 & 10.07 \\
\hline
\end{tabular}


The majority had been diagnosed with cancer for less than five years (2013-2018), overall $81.36 \%$, but there is a tendency that the longer life expectancy was found in those with cervical cancer. More cervical cancer respondents with advanced stage were found to be survivor (25\%), although most respondents of either cancer had no idea about their cancer stage $(40.86 \%$ in total). Table 2 shows that in 2007-2012 (more than five years of life expectancy since 1st cancer diagnosis was established) there were $25 \%$ and $12.23 \%$ respondents of cervical and breast cancer respectively, being long term survivors (more than five years since diagnosis). This indicates that the survival rate of breast and cervical cancer is particularly long, which makes both types of cancer chronic diseases requiring long-term care. Chemotherapy (39.29\%) and surgery (54.68\%) were being the top intervention for managing cervical and breast cancer respectively. In advanced stage, most cervical cancer respondents undertook a more complex regiment, which is a modification of surgery and chemoradiotherapy $(15 \%)$, while most advanced stage breast cancer respondents got the combination of surgery and chemotherapy only (12.95\%). More untreated cervical cancer respondents found in this study (22.86\%). Table
2 shows the characteristic of primary data related to cancer diagnosis and therapy in details.

After getting rid the data of 44 untreated respondents and 114 respondents who had no idea about their cancer stage ( $53 \%$ of initial $n=279)$, further analysis by using Spearman Rank correlation test was conducted to analyze the correlation between time of first diagnosis and type of therapy with current stage of cancer, and Mann-Whitney $U$ test for analyzing the differences of time of first diagnosis, type of therapy, and current stage of cancer between cases. The new sample size for this analysis was 58 and 73 for cervical and breast cancer respectively $(n=131)$.

Table 3 shows that there was a quite strong correlation between time of first diagnosis and current stage of cancer $(\rho=-.409 ; p=.000)$, but there was no significant correlation between type of therapy and current stage of cancer ( $p=.147)$. Table 4 shows that the first time of diagnosis and the type of therapy were significantly different between cases $(p=.039$ and $p=.000$ respectively), but the current stage of cancer was not significantly different $(p=.239)$. It seemed that the type of therapy had no significant effect towards current stage of cancer. Further study needs to be conducted to prove this preposition/hypothesis.

Table 2. Primary data

\begin{tabular}{|c|c|c|c|c|}
\hline \multirow{2}{*}{ Characteristics } & \multicolumn{2}{|c|}{ Cervical cancer $(n=140)$} & \multicolumn{2}{|c|}{ Breast cancer $(n=139)$} \\
\hline & Frequency & $\%$ & Frequency & $\%$ \\
\hline \multicolumn{5}{|l|}{ Firstly diagnosed } \\
\hline 2018 & 0 & 0.00 & 8 & 5.76 \\
\hline 2017 & 14 & 10.00 & 25 & 17.99 \\
\hline 2016 & 25 & 17.86 & 16 & 11.51 \\
\hline 2015 & 32 & 22.86 & 45 & 32.37 \\
\hline 2014 & 28 & 20.00 & 11 & 7.91 \\
\hline 2013 & 6 & 4.29 & 17 & 12.23 \\
\hline 2012 & 10 & 7.14 & 7 & 5.04 \\
\hline 2011 & 14 & 10.00 & 2 & 1.44 \\
\hline 2010 & 8 & 5.71 & 3 & 2.16 \\
\hline 2009 & 0 & 0.00 & 2 & 1.44 \\
\hline 2008 & 3 & 2.14 & 1 & 0.72 \\
\hline 2007 & 0 & 0.00 & 2 & 1.44 \\
\hline \multicolumn{5}{|l|}{ Current stage } \\
\hline I & 8 & 5.71 & 7 & 5.04 \\
\hline II & 39 & 27.86 & 18 & 12.95 \\
\hline III & 31 & 22.14 & 50 & 35.97 \\
\hline IV & 7 & 5.00 & 5 & 3.60 \\
\hline Unknown & 55 & 39.29 & 59 & 42.45 \\
\hline \multicolumn{5}{|l|}{ Type of therapy } \\
\hline Surgery & 6 & 4.29 & 76 & 54.68 \\
\hline Chemotherapy & 55 & 39.29 & 22 & 15.83 \\
\hline Radiotherapy & 7 & 5.00 & 2 & 1.44 \\
\hline Surgery + chemotherapy & 6 & 4.29 & 18 & 12.95 \\
\hline Surgery + radiotherapy & 1 & 0.71 & 1 & 0.72 \\
\hline Chemotherapy + radiotherapy & 12 & 8.57 & 1 & 0.72 \\
\hline Surgery + chemotherapy + radiotherapy & 21 & 15.00 & 7 & 5.04 \\
\hline Untreated & 32 & 22.86 & 12 & 8.63 \\
\hline
\end{tabular}


Table 3. Correlation between variables

\begin{tabular}{|c|c|c|c|}
\hline $\begin{array}{c}\text { Independent } \\
\text { variable }\end{array}$ & Dependent variable & $\begin{array}{c}\text { Rho ( } \rho) \\
\text { coefficient }\end{array}$ & $\begin{array}{l}\text { P value } \\
\text { (Sig.) }\end{array}$ \\
\hline Time of first diagnosis & Current stage of cancer & -.409 & .000 \\
\hline
\end{tabular}

Table 4. The differences between type of therapy and current stage of cancer between cases

\begin{tabular}{ccc}
\hline Variable & Z value & P value (sig.) \\
\hline Time of first diagnosis & -2.067 & .039 \\
Type of therapy & -6.717 & .000 \\
Current stage of cancer & - & .239 \\
\hline
\end{tabular}

\section{DISCUSSION}

Based on study results, the age of women living with cervical and breast cancer in Surabayan community has been slowly shifting from elderly or late adulthood to middle and early adulthood if compared to the national cancer situation in 2013. Nowadays, those with breast cancer were mostly late and middle adult female $(29.5 \%$ and $26.62 \%$ respectively), while those with cervical cancer were mostly late adult and female elderly $(40 \%$ and $32.86 \%$ respectively); but the number of early adult and adolescent female with cancer cannot be ignored (7.17\% in total). It seemed that breast cancer happens in younger age compared to cervical cancer. Generally, the mortality risk of both cancers increased with age which may affect the mortality of malignancy for South East Asian women.

It is known that the age group of 25-34, 35-44, and 45-54 years old are the age group with a high prevalence of cancer. This age group is more at risk for cancer because of unhealthy behavioral factors and eating patterns (7). There were six cancer-related risk behaviors, namely: high consumption of alcohol, high consumption of saturated fat, low consumption of fruits and vegetables, insufficient exercise, smoking, and low consumption of fiber (10). The highest proportions of people who smoke, were obese, and often consume high fatty foods were in the age group of 25-34, 35-44, and 45-54 years old. Meanwhile, the habit of consuming burned/baked food and consuming preserved foods tends to be higher in younger age group (7). In general, there is a lack of fruit and vegetable consumption in all age groups; it is the highest risk factor. Result of a comprehensive meta-analysis showed that intake of fruits and vegetables was positively associated with prevalence of non-smokers and high physical activity (11); in which these two aspects controvert two kinds of cancer-related behaviors above.
Most respondents were high school graduated (77.06\%) and being housewives (59.14\%). It could be assumed that most respondents had no income other than spouse or family contributions to address daily expenses. The condition of cancer was even exacerbates dependence on others. But luckily most respondents were married $(77.06 \%)$ and living with spouse and children $(70.25 \%)$, so that it could be assumed that they got sufficient family support. A study towards 188 cancer patients in Turkey showed that there was a negative relationship between loneliness, hopelessness, and perceived social support from family (12). In cancer, family support could reduce the feeling of loneliness and hopelessness. A few number of unmarried/single women were also found in this study (8.24\%). A study towards 7.445 women with cervical cancer in the United States showed that unmarried women have greater risk of late stage diagnosis (13).

In this study context, all respondents utilize public health services to manage cancer $(100 \%)$, such as getting therapy (referral from PHC to public hospital), or supplemental services like counseling and nutritional support (milk, supplement, and vitamin). GDP was not specifically identified in this study. It could be assumed that their socioeconomic status was lower middle, and none expressed the experience of referral to private clinic/hospital. Respondents needed to wait in a long queue in the public health services, which sometimes are lacking of supportive treatment because of resources limitation (human, budget, utilities, etc.). It was commonly observed that, even after diagnosis, the cancer patients needed to wait so long before entering the oncology service because of long waiting queues in the public health system (14).

Chemotherapy (39.29\%) and surgery (54.68\%) were being the top intervention choices in managing cervical and breast cancer respectively. Results showed that there was a significant difference of type of therapy between cervical and breast cancer $(p=.000)$, but no 
correlation was found between type of therapy and current stage of cancer $(p=.147)$. In advanced stage, most cervical cancer respondents undertook a more complex regiment, which is a modification of surgery and chemo-radiotherapy (15\%), while most advanced stage breast cancer respondents got the combination of surgery and chemotherapy only (12.95\%). There were $15,77 \%$ respondents who were already diagnosed with cancer but had not yet been subjected to any cancer treatment. A study in the United States towards 51.549 cases of breast cancer revealed that race or ethnicity was significantly associated with surgery, radiotherapy, insurance status ( $p<.0005$ for each), and the survival rate $(p<.001)(15)$. In this study, ethnicity was not specifically identified, but most respondents seemed to be Javanese.

The majority had been diagnosed with cancer for less than five years (81.36\%), and more women living with cervical cancer found to be long term cancer survivors (25\%). They had been living for more than five years since cancer diagnosis was established. There was a significant difference of the time of first diagnosis between cervical and breast cancer $(p=.039)$. In this study we found more acute survivors in breast cancer cases $(17.99 \%)$, while more short term and long term survivors were found in cervical cancer cases $160.71 \%$ and $25 \%$ respectively). This potentially related to ageprone to cancer in this study context, of which result showed that there was a tendency of breast cancer to happen in younger age compared to cervical cancer.

There was a quite strong correlation between time of first diagnosis and current stage of cancer $(p=-.409$; $p=.000$ ); the negative value in the correlation coefficient means that the latest time of first cancer diagnosis then the lowest current stage of cancer; but longer time to diagnosis did not fully explain differences in cancer stage especially in women living with breast cancer (16). Stage at diagnosis is a strong predictor of breast cancer mortality. Five-year survivals rates are better for early stage (88\% for women diagnosed at stage I and $78 \%$ for diagnoses at stage II) than for advanced stage (16). Similar study related to correlation between time of first diagnosis and current stage of cancer specifically in cervical or breast cancer is none to be found yet.

Most respondents of cervical cancer perceived that their current stage of cancer was early (stage II: $27.86 \%$ ), while most respondents of breast cancer perceived that their current stage was advanced (stage III: $35.97 \%$ ). Result showed that there was insignificant difference of current stage of cancer between cervical and breast cancer $(p=.147)$. Medical records were not identified in this study; the information of current stage of cancer was purely given by the respondents. There was a possibility that the respondents' perception about their current stage of cancer was wrong, but researcher did not confirm the respondents' answer to this question with the medical records. This has been the study limitation. A study in Korea implicitly showed that there were knowledge gaps between patients' perceived and actual stage of cancer (17). The lower stage found in cervical cancer respondents in this study possibly happened due to the same reason with the above study.

There were 114 respondents, who did not know their cancer stage, were found in this study (40.86\%). This indicates the lack of communication between health practitioner and the patients. Sometimes, insufficient time to give health education was provided in PHC setting due to high workload related to the big daily number of patients. The waiting time to get health service in $\mathrm{PHC}$ is also being a key performance indicator of PHC work performance. One way to test the accuracy of communication between doctors and patients is by evaluating the consistency between patient perception of cancer stage and the stage given in medical records (17). Other than communication reason, there is a possibility that cancer stage was not identified yet to limitation in laboratory and radiology tests related to cancer diagnosis, such as waiting time for biopsy because all respondents used public health services. Faster diagnosis and initial therapy could be affected by the usage of public or private health services. Late diagnosis was often resulted from inefficiency of the prevention policies coupled with difficulty accessing the public health network (14).

Patients with cancer continuously need information about cancer and the disease process, diagnosis and treatment, nutritional needs, psychosocial and spiritual support, etc. This increases the importance of providing sufficient time for giving health education towards cancer patients in PHC setting. The information needs of breast cancer patients at diagnosis have been studied extensively. However, with cancer survival is improving, the era of cancer care has entered a more chronic phase with an associated paucity of data related to longer term information requirements.

Cancer management in community context in Surabaya is really a complex matter, in term of in-house service in the PHC and home visit service. Resources limitation is sometimes being the reason of low achievement in community's cancer management. Other than that, the life expectancy of people living with cancer increases steadily, making cancer being one of the NCDs with long-term burden that needs long-term supports and palliative care. Early detection of breast cancer in adolescent and early adult female needs to be promoted aggressively by community nurse to minimize the prevalence in middle up adulthood. Special attention needs to be given towards women living with cervical and breast cancer affecting the majority of people living with cancer today, so that their quality of life could be optimized, and the country's burden related to health expenditure could be decreased continually. 


\section{CONCLUSIONS}

The demographic characteristic of women living with cervical and breast cancer in Surabaya has been slowly shifting from elderly or late adulthood to middle and early adulthood. Breast cancer happens in younger age compared to cervical cancer. More long-term survivors were found in women living with cervical cancer. The first time of diagnosis and the type of therapy were significantly different between cases, but the current stage of cancer was not significantly different. There was a strong significant correlation between time of first diagnosis and current stage of cancer. Aggressive cancer promotion and prevention strategy should be immediately implemented into public through PHC services to establish a better cancer management in the community and to assure maximum benefit for the country.

\section{DECLARATIONS}

\section{Ethical approval}

This study protocol has been reviewed for ethical purposes. Ethical clearance was issued by Faculty of Nursing, Universitas Airlangga, Surabaya, Indonesia, with certificate number of 681-KEPK. All respondents had signed the consent forms and expressed the agreement to participate in this study.

\section{Competing of Interest}

I declare that I do not have any competing interest

\section{Acknowledgement}

This study was funded by the Center of Food and Nutritional Research, Institute of Research and Community Service, Widya Mandala Catholic University Surabaya, by Grant number: 077a/WM01.5.2/N/2018. This publication was supported by Faculty of Nursing, Widya Mandala Catholic University Surabaya.

\section{REFERENCES}

1. Kaplan M. The Hispanic outlook in higher education. Paramus. 2008; 18(17): 42-44.

2. Demment MM, Peters K, Dykens JA, Dozier A, Nawaz $H$, McIntosh S, Smith JS, Sy A, Irwin T, Fogg TT, Khaliq M, Blumenfeld R, Massoudi M, De Ver Dye T. Developing the evidence base to inform best practice: a scoping study of breast and cervical cancer reviews in low- and middleincome countries. PLoS ONE. 2015; 10(9): e0134618.

3. Denny L, de Sanjose S, Mutebi M, Anderson BO, Kim J, Jeronimo J, Herrero R, Yeates K, Ginsburg O, Sankaranarayanan R. Interventions to close the divide for women with breast and cervical cancer between lowincome and middle-income countries and high-income countries. The Lancet Series: Health, Equity, and Women's Cancers 2. 2017; 389: 861-870.

4. Ginsburg O, Bray F, Coleman MP, Vanderpuve V, Eniu A, Kotha SR, Sarker M, et al. The global burden of women's cancers: a grand challenge in global health. The Lancet Series: Health, Equity, and Women's Cancers 2. 2017; 389: $847-860$.

5. Campo RA, Lenjek KL, Gaylord-scott N, Faurot KR, Smith S, Asher G, Porterfield $D$, et al. Weathering the seasons of cancer survivorship: mind-body therapy use and reported reasons and outcomes by stages of cancer survivorship. Supportive Care in Cancer Survivorship. 2016; 24(9): 3783-3791.

6. Tejawinata S. Surabaya, The City of Palliative: Its Image and Charm (in Bahasa Indonesia). 2012. Surabaya: Airlangga University Press.

7. Ministry of Health, Republic of Indonesia. National Cancer Situation in 2013 (in Bahasa Indonesia). 2015. Retrieved from: http://www.depkes.go.id/resources/download /pusdatin/infodatin/infodatin-kanker.pdf

8. American Cancer Society (ACS). Cervical cancer. Smart Engage: In Depth Report. 2017. USA: Johns Creek.

9. American Cancer Society (ACS). Breast cancer. Smart Engage: In Depth Report. 2017. USA: Johns Creek.

10. Fox RS, Mills SD, Roesch SC, Sotres-Alvarez D, Gonzalez P, Bekteshi V, Cai J, et al. Perceptions of cancer risk/efficacy and cancer-related risk behaviours: results from the $\mathrm{HCHS} / \mathrm{SOL}$ sociocultural ancillary study. Health Educ Behav. 2018; 45(5): 790-799.

11. Grosso G, Micek A, Godos J, Pajak A, Sciacca S, et al. Health risk factors associated with meat, fruit and vegetable consumption in cohort studies: a comprehensive meta-analysis. PLoS One. 2017; 12(8): e0183787.

12. Pehlivan S, Ovayolu O, Ovayolu N, Sevinc A, Camci C. Relationship between hopelessness, loneliness, and perceived social support from family in Turkish patients with cancer. Support Care Cancer. 2012; 20: 733-739.

13. Pelletier MS. Factors associated with late stage diagnosis of cervical cancer in the United States. Dissertation. 2016. Minnesota: College of Health Sciences, Walden University.

14. Ferreira NAS, de Carvalho SMF, Valenti VE, Bezerra IMP, Batista HMT, de Abreu LC, Adami F, et al. Treatment delays among women with breast cancer in a low socioeconomic status region in Brazil. BMC Women's Health. 2017; 13: 1-8.

15. Holt A. Assessing Disparities in Breast Cancer Treatment and Survival among Women Diagnosed with Late-Stage Breast Cancer in The U.S. Using SEER 18 Data. 2016. Tallahassee, Florida: The Florida Agricultural and Mechanical University College of Pharmacy and Pharmaceutical Sciences.

16. Warner ET, Tamimi RM, Hughes ME, Ottesen RA, Wong $\mathrm{YN}$, Edge SB, Theriault RL, et al. Time to diagnosis and breast cancer stage by race/ethnicity. Breast Cancer Res Treat. 2012; 136: 813-821.

17. Shim HY, Park JH, Kim SY, Shin DW, Shin JY, Park BY, Huh JS, et al. Discordance between perceived and actual cancer stage among cancer patients in Korea: a nationwide survey. PLOS ONE. 2014; 9(5): e90483. 